\title{
RELEASE AND PERMEATION OF INDOMETHACIN FROM PHOSPHOLIPID COMPLEX FILM GENERATED FROM SPRAY FORMULATIONS
}

\author{
WILAIPORN BUATONG ${ }^{1}$, TITPAWAN NAKPHENG ${ }^{1}$, JANWIT DECHRAKSA ${ }^{2}$, \\ SAO-AKE SAISAMUTH ${ }^{3}$, WIPATCHA KONGKHAO ${ }^{3}$ and TEERAPOL SRICHANA ${ }^{1,3 *}$ \\ 'Drug Delivery System Excellence Center, Faculty of Pharmaceutical Sciences, \\ Prince of Songkla University, Hat Yai, Songkhla 90112, Thailand \\ ${ }^{2}$ Faculty of Veterinary Science, Prince of Songkla University, Hat Yai, Songkhla 90112, Thailand \\ ${ }^{3}$ Department of Pharmaceutical Technology, Faculty of Pharmaceutical Sciences, \\ Prince of Songkla University, Hat Yai, Songkhla 90112, Thailand
}

\begin{abstract}
An indomethacin topical spray was prepared using lecithin and a cholesterol derivative as a phospholipid complex in a film. Polyvinylpyrrolidone (PVP) was used as a film-forming agent. Cytotoxicity to the keratinocytes and fibroblast cells was performed. Drug penetration through keratinocytes was evaluated. The results reveal that the PVP concentration provided fine droplets under a microscope with a low contact angle $\left(12.07^{\circ}-22.53^{\circ}\right)$. Incorporating PVP in the formulation reduced the hydrodynamic radius or size by 20 times. The SEM and TEM results showed smoother surfaces of the thin film for larger quantities of the PVP filmforming agent in the formulations. It also gave the highest drug penetration when the PVP was $0.5 \%$. However, the film-forming agent can also act as a control release barrier. The percent viabilities of the human keratinocytes and fibroblasts were higher in the indomethacin spray phospholipid complex thin film formulation than the pure drug.
\end{abstract}

Keywords: Indomethacin, topical spray, controlled release, phospholipid complex, thin film

Indomethacin (IMC) is a nonsteroidal antiinflammatory drug (NSAID). The major drawbacks of using oral drug delivery are oral and gastrointestinal side effects (1-3). Indomethacin has been shown to be very appropriate for topical delivery (4). Moreover, it is a suitable candidate for formulation in topical pharmaceutical dosage forms based on in vitro topical anti-inflammatory activity (5). The amorphous state of indomethacin presented a high permeation rate across hairless rat skin (6). However, the poor solubility of the IMC is still the limitation of formulation preparation. The delivery systems, which have been used to overcome the drug solubility problem, include loaded nanostructured lipid carriers, nanoparticle-based topical gel, and nanostructure supramolecular hydrogel (7-10). The encapsulation system promoted more safety and more drug availability at the site of action (10).

A phospholipid complex is an encapsulation system and widely used in topical delivery that includes scar tissue to skin cancer (11-13). This system has given very effective permeation enhance- ment in both hydrophilic and lipophilic drugs (14). Natural lipids such as lecithin obtained from egg yolk or soybean have been used for incorporation in phospholipid complex drug delivery systems. The lecithin from egg yolk gives superior properties for topical use in terms of $\mathrm{pH}$; the $\mathrm{pH}$ decreases (5.8 to $4.0)$ as the lecithin concentration increases $(0.5$ to 10 $\mathrm{mg} / \mathrm{mL}$ ) (15). Even, the hydration effect obtained by the egg phospholipid complex was significantly higher than a soya phospholipid complex according to an in vivo test (16).

A cholesterol incorporation system showed improved rigidity and stability of a phospholipid complex (17-18). The vesicle's elasticity indicated by both Young' modulus and the bending modulus was increased in the cholesterol modified vesicle compared with the unmodified system (18). However, the concentrations of cholesterol and phospholipid should be optimized to adjust the stability and the degree of destabilization of the system (17). Ethanol enhances the permeability, and an increased concentration of ethanol in the formulation incre-

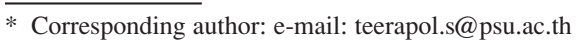


ased the permeation across the fully-interdigitated membrane (dipalmitoyl phosphatidyl-choline/cholesterol binary mixture) (19). The presence of ethanol also showed a larger phospholipid complex due to a decrease in the interfacial tension or the induction of interdigitation (16).

Kollidon $^{\circledR}$ VA64 is a vinyl pyrrolidone/vinyl acetate copolymer at a ratio of $6: 4$. It has several pharmaceutical applications such as a tablet binder, a granulating agent, and a film former (20). This copovidone polymer exhibited a very good safety profile in animal carcinogenicity and chronic toxicity tests (21). Moreover, PVP had been developed as an ammonia sensor film, and PVP alone showed a smoother surface compared to modified PVP with graphene oxide (22).

However, till date, none of the phospholipid complex-based NSAID formulations have become part of a developed vaporized product, which could construct a thin layer of the film after spraying. Therefore, the main objective of this study was to formulate a highly permeable indomethacin phospholipid complex using Kollidon ${ }^{\circledR}$ VA64 as the filmforming polymer and pressurize the formulation via a filling method with HFA-134a. The physicochemical properties of the sprayed film and the droplets were evaluated. The cytotoxicity studies and in vitro permeability of the film formulation were performed.

\section{EXPERIMENTAL}

\section{Chemicals, reagents and other supplies}

IMC, lecithin, and cholesterol were procured from Sigma-Aldrich, St. Louis, USA. HFA-134a was obtained from Mexichem UK Ltd., UK. Kollidon ${ }^{\circledast}$ VA64 was a generous gift from BASF Chemical Company, Germany. All other reagents and chemicals were of analytical grade.

\section{Preparations of IMC topical spray}

Five formulations were prepared with IMC $(0.8 \% \mathrm{w} / \mathrm{w})$ along with variable ingredients (Table 1). Lecithin, Kollidon ${ }^{\circledast}$ VA64, menthol, and cholesterol were dissolved and mixed in absolute ethanol until a clear solution was obtained before adding the IMC. Four $\mathrm{mL}$ of the formulation was pipetted into a glass canister (Schott AG, Germany). Then a 50 $\mu \mathrm{L}$ metering valve was immediately crimp-sealed onto the canister with an aerosol crimping and filling machine (model 2016, Pamasol Willi Mäder, Switzerland). The canisters were then filled with $8 \mathrm{~mL}$ propellant HFA-134a.

\section{Imaging and contact angle measurement of spray droplet}

The Olympus, BX61 polarized light microscope was used for observation of spray droplets under phase contrast mode. The formulation was sprayed on a glass slide from a distance of $10 \mathrm{~cm}$ before the observation of spray droplets and film appearance.

The static sessile drop method was measured using a Contact Anglemeter (OCA 15 EC, Dataphysics Instruments GmbH, Germany). The angle formed between the liquid-air interface is the contact angle. Current-generation systems employed a high-resolution camera and software to capture and analyze the contact angle. The droplet was vertically dropped down by a syringe pointed and deposited onto the sample surface. The high-resolution camera captured the image, which could then be analyzed using image analysis software. The size of the droplet increased gradually so that it grew proportionally and the contact angle remained. By taking pictures incrementally as the droplet grew, the user could acquire a set of data to get a good average.

Table 1. Preparations of indomethacin (IMC) spray formulation (\%w/w).

\begin{tabular}{|c|c|c|c|c|c|}
\hline Ingredients & $\mathrm{F} 1$ & $\mathrm{~F} 2$ & F3 & $\mathrm{F} 4$ & F5 \\
\hline IMC & 0.8 & 0.8 & 0.8 & 0.8 & 0.8 \\
\hline Ethanol & 32.3 & 31.7 & 30.7 & 30.2 & 29.2 \\
\hline Lecithin & - & 0.5 & 0.5 & 0.5 & 0.5 \\
\hline Cholesterol & - & 0.1 & 0.1 & 0.1 & 0.1 \\
\hline Glycerol & - & - & 0.5 & 0.5 & 0.5 \\
\hline Kollidon $^{\circledR}$ VA64 & - & - & 0.5 & 1.0 & 2.0 \\
\hline Menthol & 0.2 & 0.2 & 0.2 & 0.2 & 0.2 \\
\hline HFA134a & 66.7 & 66.7 & 66.7 & 66.7 & 66.7 \\
\hline
\end{tabular}




\section{Hydrodynamic size of IMC in simulated spray product system}

Particle hydrodynamic size was obtained using a Zetasizer Nano ZS (Malvern, UK) at $25^{\circ} \mathrm{C}$. The measurement was set for backscatter detection at an angle of $173^{\circ}$. The simulated spray product system consisted of the IMC formulation and methylene chloride in the ratio of $4: 8$. This mimicked a pressurized spray system as the dielectric constant and polarity of methylene chloride are close to that of the HFA-134a. A quartz cuvette was filled with $1 \mathrm{~mL}$ of the simulated spray system and hermetically sealed. Each sample was analyzed in triplicate.

\section{Scanning electron microscopy (SEM) and Transmission electron microscopy (TEM) of the IMC film}

The morphology of the sprayed film was examined by SEM (JSM-5800 LV, JOEL, Tokyo, Japan). The samples were sprayed on a cover glass slide. The slides were then cut to visualize the crosssection of the sprayed film. The IMC phospholipid complex samples were dropped onto a 200 mesh copper grid. The dried samples were kept in a desiccator overnight before examination by TEM (JEM2010; JEOL, Tokyo, Japan).

\section{Fourier Transform Infrared Spectroscopy (FT-IR) of indomethacin formulations spray \\ Infrared spectroscopy was used to identify the} interaction of IMC with other excipients using potassium bromide (KBr) disc method. IMC formulation was sprayed on dried $\mathrm{KBr}$ and carefully mixed and compressed with 10 ton of hydraulic press for 1-2 min into a pellet. The pellet was placed in a magnetic holder. The FT-IR spectra were recorded between 4000 and $400 \mathrm{~cm}^{-1}$ by an accumulation of 16 scans using a Spectrum One (PerkinElmer, MA, USA).

\section{High-performance liquid chromatography (HPLC) assay}

Quantitative analysis of the IMC for the dissolution and permeation properties was assayed using HPLC. The mobile phase was $25: 75$ of $2.0 \mathrm{mM}$ sodium acetate buffer and the methanol flow rate was set at $1 \mathrm{~mL} / \mathrm{min}$. The system was separated with reverse phase $\mathrm{C} 18$ as the stationary phase (Thermo ${ }^{\oplus}$ RP18, $150 \times 4.6 \mathrm{~mm} \mathrm{ID,} 5 \mu \mathrm{m}$, USA) coupled to a $\mathrm{C} 18$ guard column at $25^{\circ} \mathrm{C}$ with $10 \mu \mathrm{L}$ injection volume and UV detection at $235 \mathrm{~nm}$. The retention time was about $10 \mathrm{~min}$. The peak areas of standard concentration of IMC were determined to obtain the calibration curves.

\section{In vitro drug dissolution from the sprayed film}

The dissolution study of the IMC topical sprays was evaluated by modified Franz diffusion cell. Three puffs of IMC were sprayed on a synthetic cellulose acetate membrane, and the film was dried for $5 \mathrm{~min}$. The sprayed side of membrane was allowed to be in contact with dissolution medium (12.5 mL) of $1 \mathrm{M}$ Hank's Balanced Salt Solution (HBSS) (Sigma, USA) and $20 \mathrm{mM}$ of 2-(N-morpholino) ethane sulfonic acid (MES) (Sigma, MA, USA) in an isotonic phosphate buffer $\mathrm{pH} 7.4$ and ethanol $(80: 20)$ ) and maintained at $37^{\circ} \mathrm{C}$. This whole assembly was kept on a magnetic stirrer, and the solution was stirred continuously using a magnetic bar at $400 \mathrm{rpm}$. Then, $200 \mu \mathrm{L}$ aliquots of the dissolution medium were replaced with fresh medium at $30 \mathrm{~min}, 1,2,3,4,6,8,10,12$, and $24 \mathrm{~h}$. The concentration of IMC was determined by HPLC. Dissolution studies were performed in triplicate. The cumulative drug dissolution $\left(\mathrm{Q}_{\mathrm{t}}\right)$ was calculated from the following equation.

$$
\mathrm{Q}_{\mathrm{t}}=V_{r} C_{t}+\sum_{\mathrm{t}=0}^{\mathrm{t}-1} V_{s} C_{i}
$$

where $C_{t}$ is the drug concentration of the receiver solution at each sampling time, the drug concentration of the $\mathrm{i}^{\text {th }}$ sample, and $V_{r}$ and $V_{s}$ are the volumes of the receiver solution and sample, respectively (23).

\section{Cytotoxicity assay}

Human keratinocytes (HaCaT) and fibroblasts (BJ cells) were used to examine the effect of the IMC spray formulations on cell viability. HaCaT and BJ cells were cultured in Dulbecco's Modified Eagle Medium (Gibco, NY, USA) and Eagle's Modified Eagle Medium (Gibco, USA), respectively at $37^{\circ} \mathrm{C}$ with $5 \% \mathrm{CO}_{2}$ and $95 \%$ humidity. These were supplemented with $10 \%$ fetal bovine serum (Gibco, $\mathrm{NY}$, USA) and 50 units $/ \mathrm{mL}$ of penicillin and 50 $\mu \mathrm{g} / \mathrm{mL}$ of streptomycin (Gibco, NY, USA).

The cells were seeded into a 96-well plate (Corning Costar, NY, USA) at a density of $1 \times 10^{5}$ cells/well. The cells were then incubated at $37^{\circ} \mathrm{C}$ under $5 \% \mathrm{CO}_{2}$ and $95 \%$ humidity for $24 \mathrm{~h}$. The toxicity of the IMC spray formulations was investigated using the methyl thiazol tetrazolium (MTT) assay. Culture medium was used as a control. Briefly, IMC formulation was sprayed once into $2 \mathrm{~mL}$ of the medium to produce a drug concentration of $400 \mu \mathrm{g} / \mathrm{mL}$. Aliquots $(100 \mu \mathrm{L})$ were loaded into 96-well plates containing cells that were seeded for $18 \mathrm{~h}$ and incubated overnight. The medium was replaced with $100 \mu \mathrm{L}$ of the fresh medium along with $50 \mu \mathrm{L}$ of MTT solution and incubated at $37^{\circ} \mathrm{C}$ under $5 \% \mathrm{CO}_{2}$ for $4 \mathrm{~h}$. The media containing MTT 
(a)
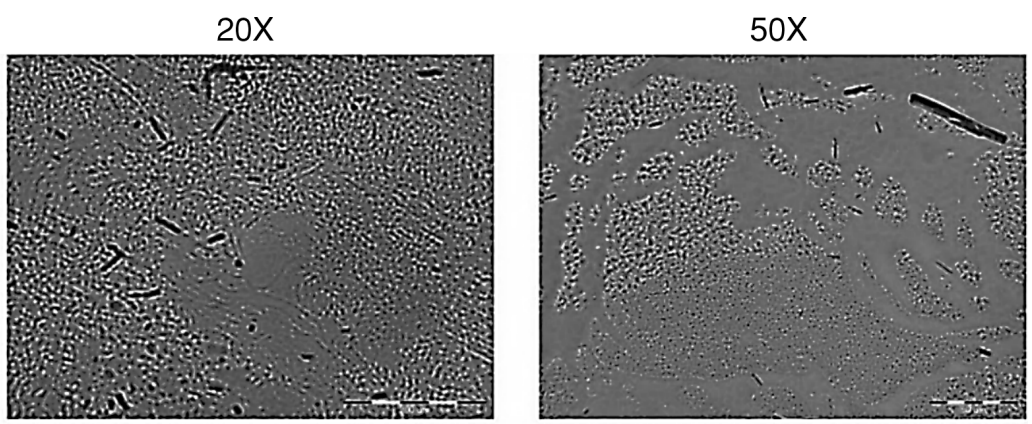

(b)
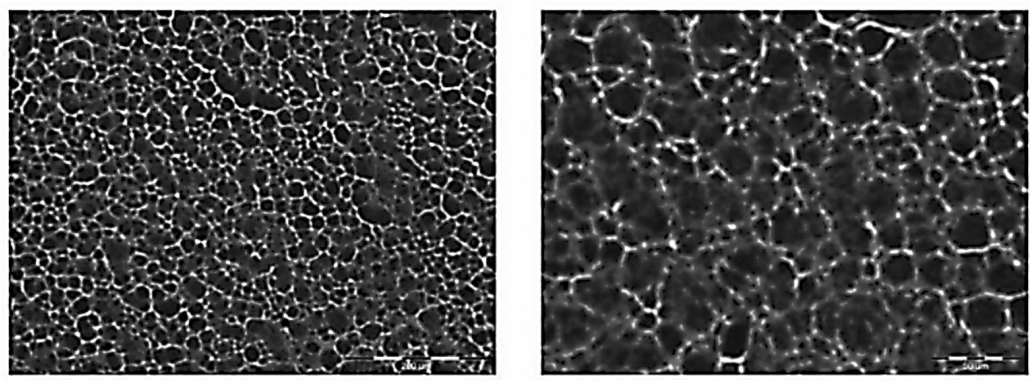

(c)
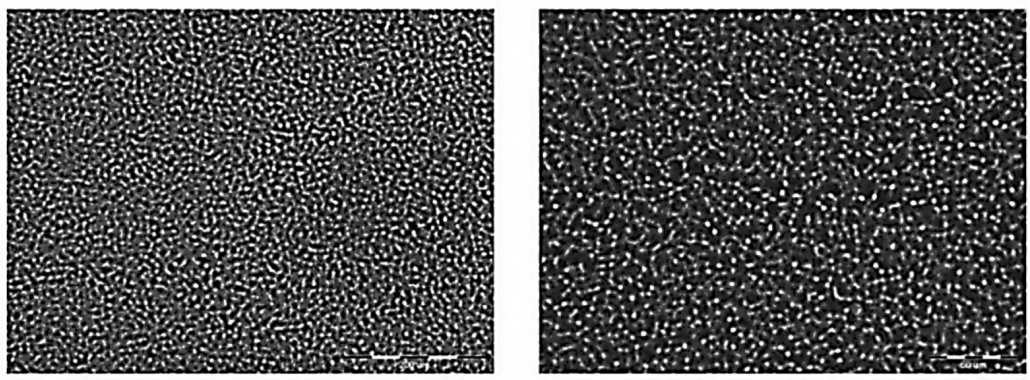

(d)
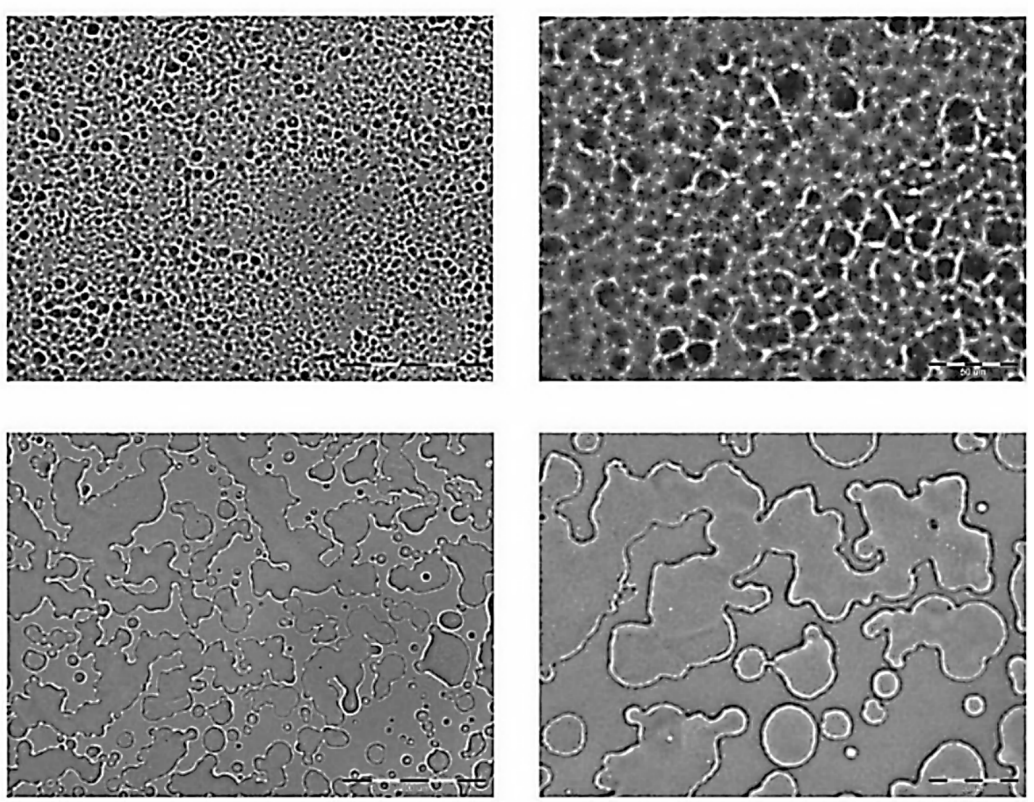

Figure 1. Spray pattern of IMC only (a), IMC phospholipid complex (b), IMC phospholipid complex with $0.5 \%$ PVP (c), IMC phospholipid complex with 1\% PVP (d) and IMC phospholipid complex with 2\% PVP (e) under polarized light microscope at two magnifications 
Table 2. Hydrodynamic particle size of IMC mimic spray formulation (Mean $\pm \mathrm{SD}, \mathrm{n}=3$ ).

\begin{tabular}{|l|c|}
\hline \multicolumn{1}{|c|}{ Formulation } & Hydrodynamic particle size (nm) \\
\hline IMC only & $610 \pm 36$ \\
\hline IMC Phospholipid complex & $493 \pm 28$ \\
\hline IMC Phospholipid complex with $0.5 \%$ PVP & $25 \pm 7$ \\
\hline IMC Phospholipid complex with $1.0 \%$ PVP & $28 \pm 7$ \\
\hline IMC Phospholipid complex with $2.0 \%$ PVP & $23 \pm 8$ \\
\hline
\end{tabular}

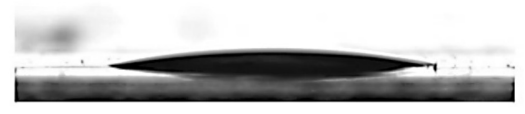

a) contact angle $=12.07^{\circ}$

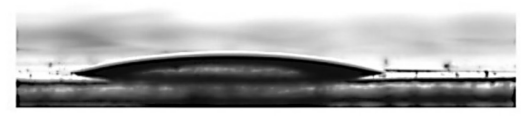

b) contact angle $=13.93^{\circ}$

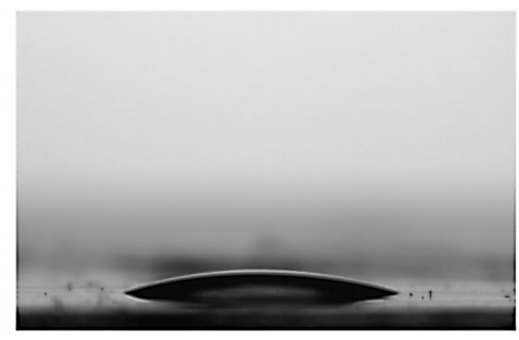

d) contact angle $=17.85^{\circ}$

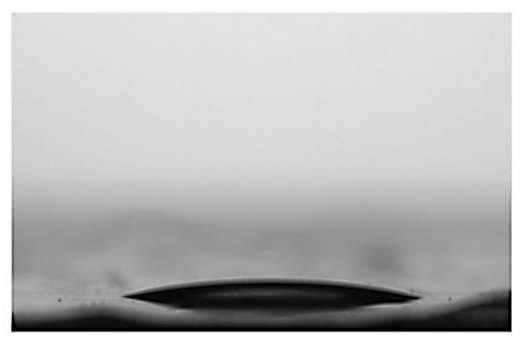

c) contact angle $=13.88^{\circ}$

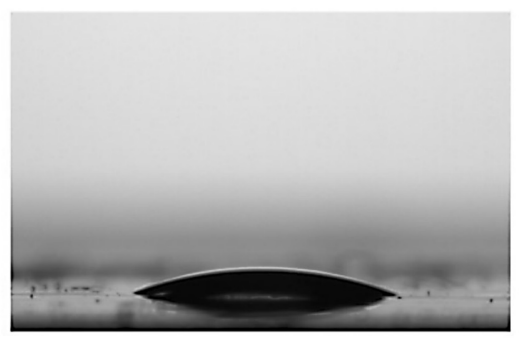

e) contact angle $=22.53^{\circ}$

Figure 2. Contact angle different film former concentration: IMC only (a), IMC phospholipid complex (b), IMC phospholipid complex with $0.5 \%$ PVP (c), IMC phospholipid complex with $1 \%$ PVP (d) and IMC phospholipid complex with $2 \%$ PVP (e)

were removed, and $200 \mu \mathrm{L}$ of dimethylsulphoxide was added. The absorbance was determined by a microplate reader at a wavelength of $570 \mathrm{~nm}$. The percentages of cell viability were calculated and compared to the control.

\section{IMC permeation across keratinocytes cells}

Human keratinocytes (HaCaT $10^{5}$ cells) were seeded into the donor compartment of a 6-well
Transwell ${ }^{\circledast}$ plate (Costar, Corning, NY, USA). The cells were mounted between two diffusion half-cells with a diffusion area of $0.64 \mathrm{~cm}^{2}$ with the epidermal side facing the donor chamber. The Transwell ${ }^{\circledast}$ plate was then incubated at $37^{\circ} \mathrm{C}$ with $5 \% \mathrm{CO}_{2}$ for $21-25$ days. The transepithelial electrical resistance of the incubated cells was optimized at $300 \Omega / \mathrm{cm}^{2}$ before further study. Transport medium at $\mathrm{pH} 7.4$ (1 M HBSS and $20 \mathrm{mM}$ MES) was added into the receiv- 


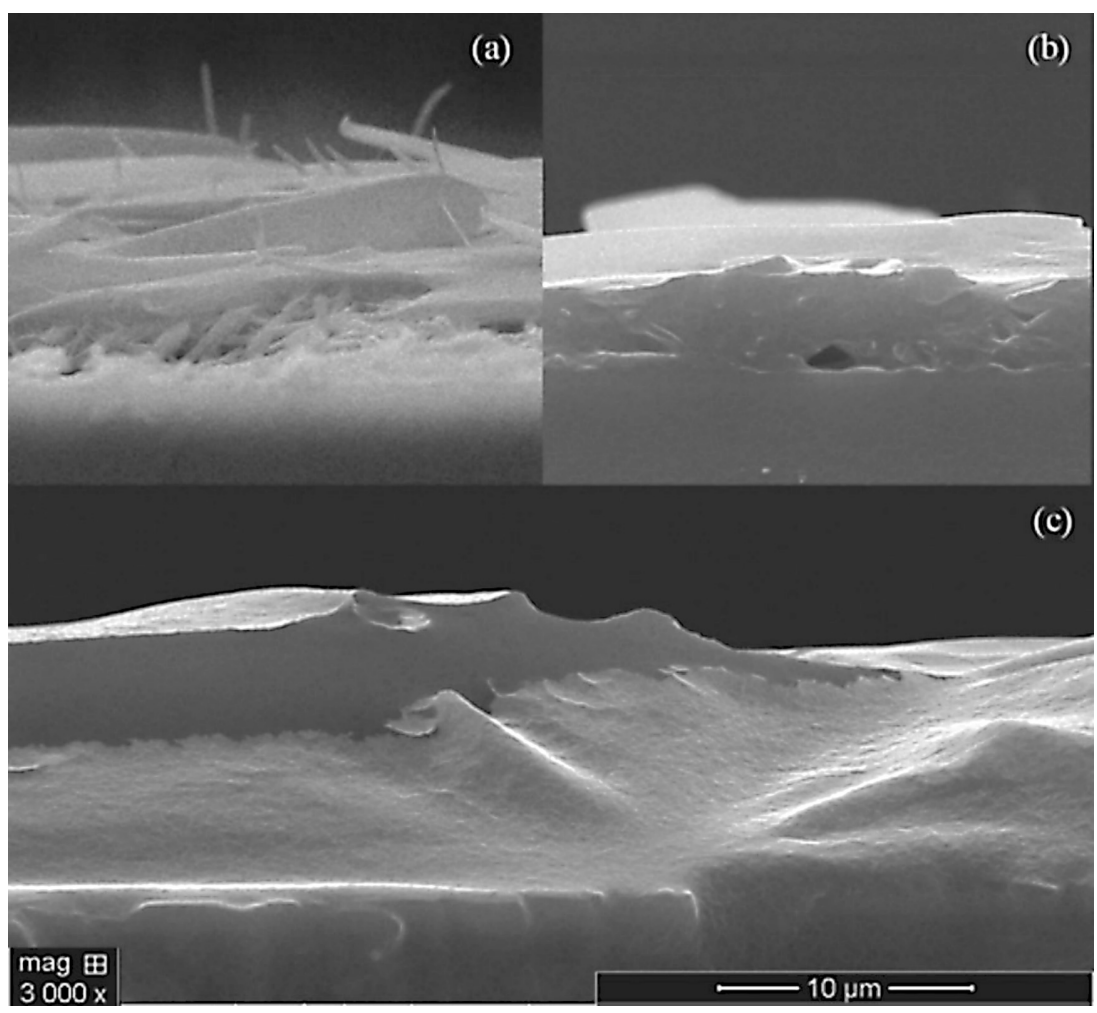

Figure 3. SEM characteristic of film over cover slide: IMC and ethanol (a), IMC phospholipid complex (b) and IMC phospholipid complex with PVP (c)

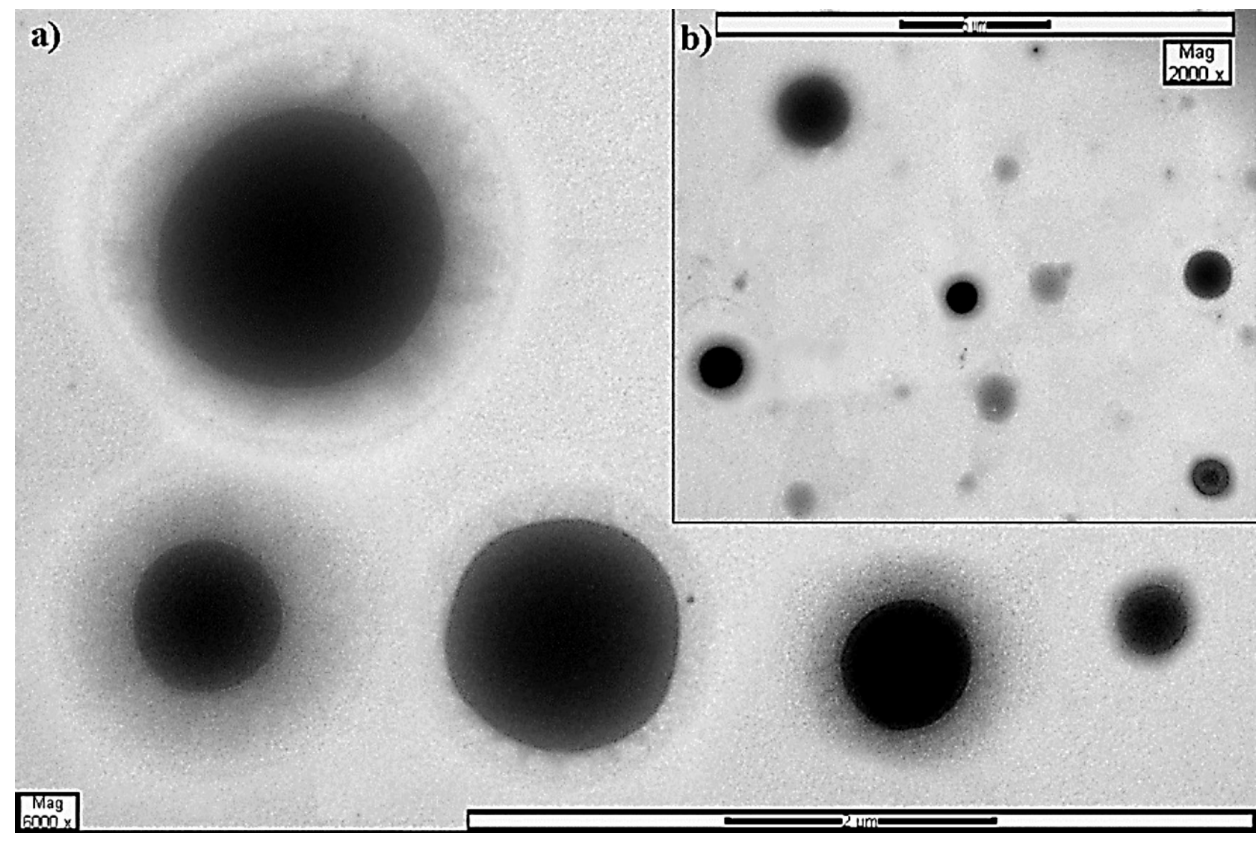

Figure 4. TEM of IMC spray in the phospholipid complex formulation under $6000 \times$ (a) and $2000 \times$ (b) magnification 


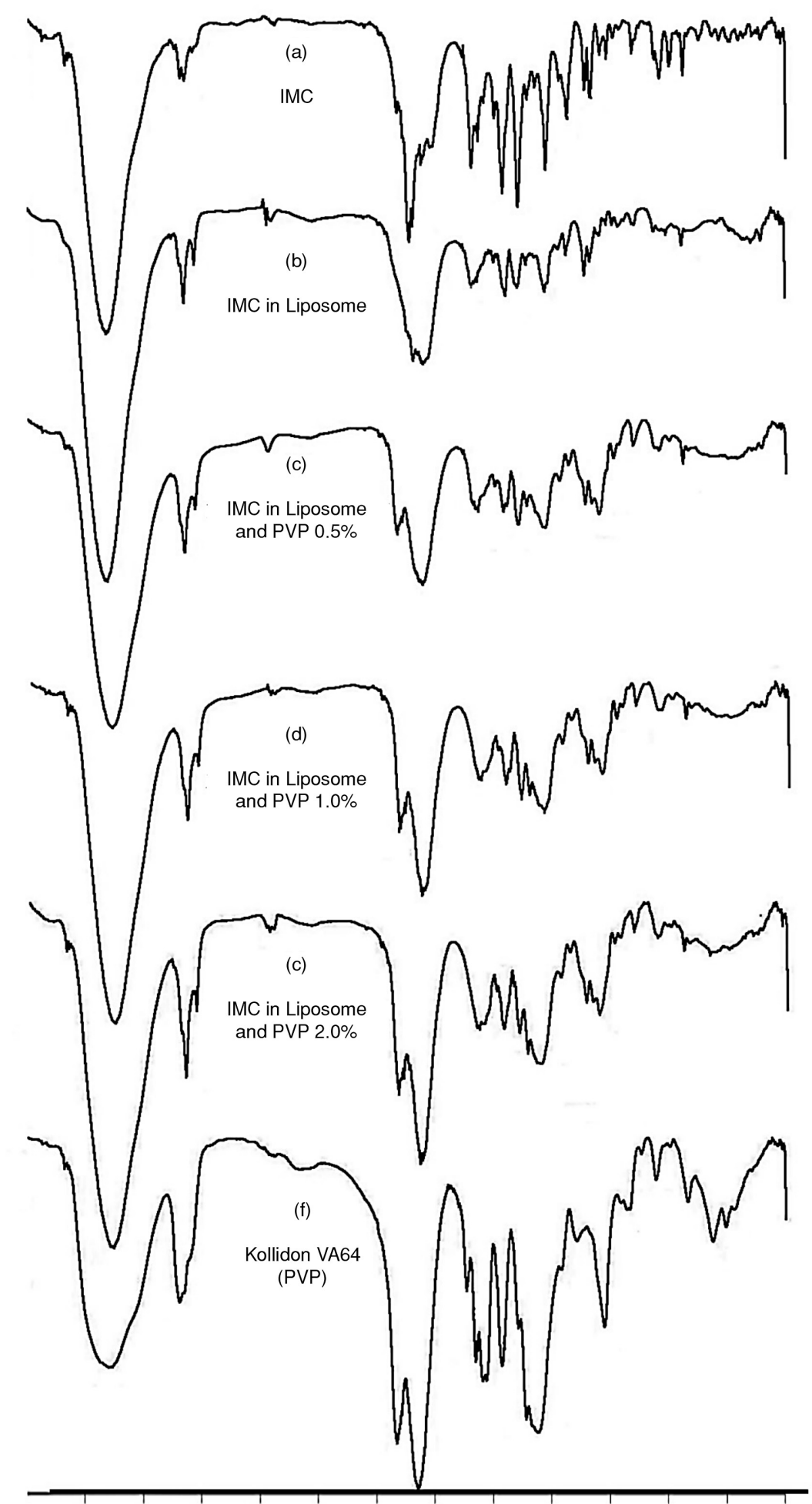

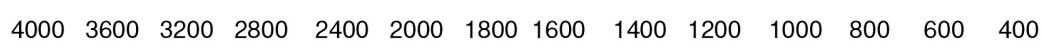
$\mathrm{cm}^{-1}$

Figure 5. IR spectrum of IMC (Pure drug) (a), IMC in liposome (b), IMC in liposome and PVP 0.5\% (c), IMC in liposome and PVP 1.0\% (d), IMC in liposome and PVP $2.0 \%$ (e) and Kollidon VA64 (PVP) (f) 
er phase. The samples were dissolved in $1.5 \mathrm{~mL}$ transport medium and placed into the donor compartment. The permeation of IMC topical spray formulations across the keratinocyte cells into the receiver compartment was sampled at 10, 20, 30, 40, 50 , and $60 \mathrm{~min}$ and further analyzed by HPLC.

\section{RESULTS}

The spray patterns and contact angles of formulation

The droplet size and shape of the film are shown in Figure 1. It was found that when the concentration of PVP increased the droplets formed a fused film. The larger contact angles were observed when PVP concentration increased especially at 2\% PVP (Fig. 2).

\section{Hydrodynamic particle size of the IMC mimicked formulation}

The hydrodynamic particle sizes of the formulations were in a range of $610 \pm 36$ to $23 \pm 8 \mathrm{~nm}$ as shown in Table 2. However, the formulations in a phospholipid complex reduced the particle size (493 $\pm 28 \mathrm{~nm}$ ), particularly within a film-forming agent PVP that the hydrodynamic size was significantly reduced to $23 \pm 8$ to $28 \pm 7 \mathrm{~nm}$.

\section{Formulation morphology under electron micro- scopy}

Figure 3 shows the SEM images of the dried coated film of the IMC with different compositions. The cross-section SEM images of the three samples (IMC in ethanol, IMC in phospholipid complex, and

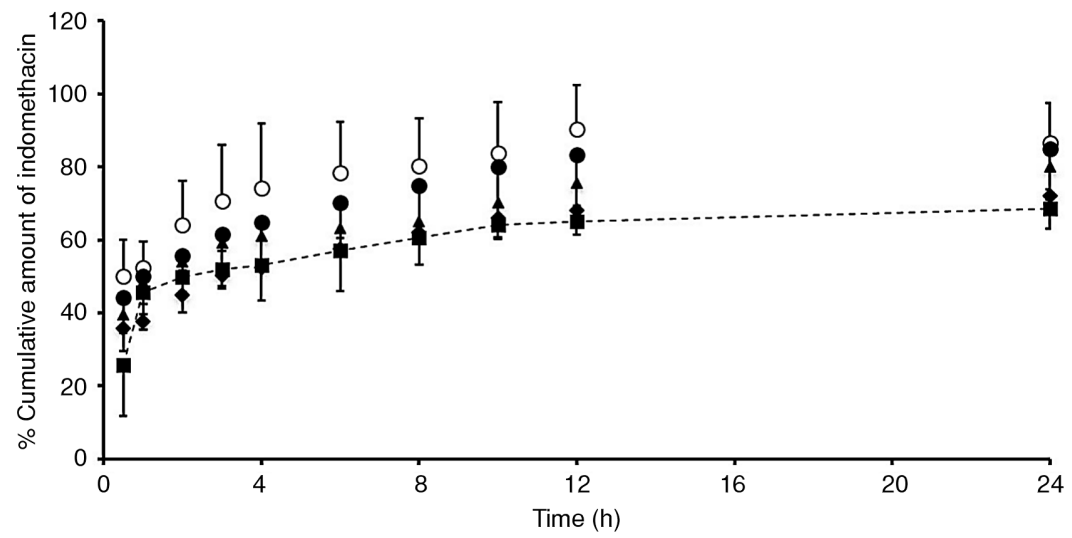

Figure 6. IMC release profiles: IMC only (black square), IMC phospholipid complex (black diamond), IMC phospholipid complex with $0.5 \%$ PVP (white circle), IMC phospholipid complex with $1.0 \%$ PVP (black circle) and phospholipid complex with $2 \%$ PVP (black triangle) $($ mean $\pm \mathrm{SD}, \mathrm{n}=3)$

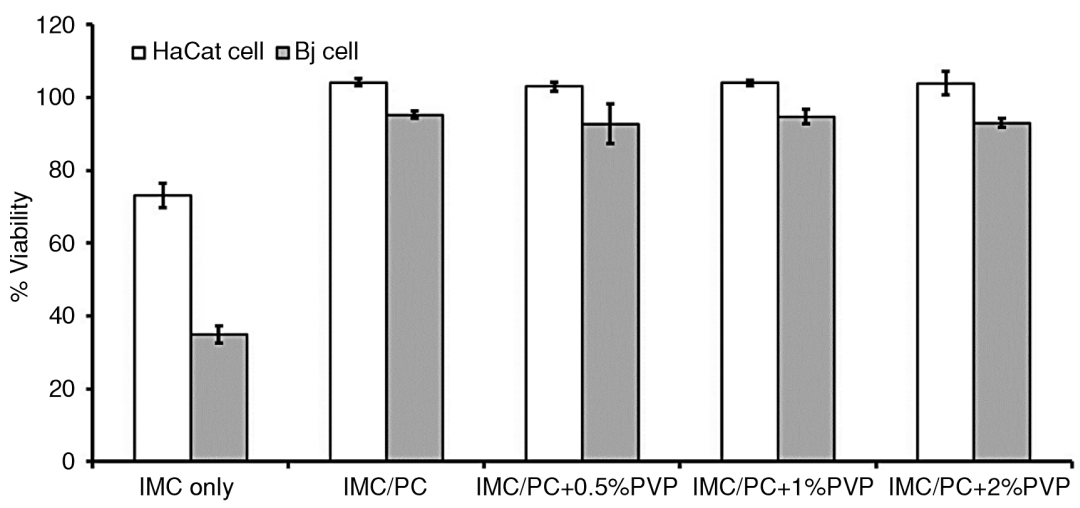

Figure 7. \%Viability of the human keratinocyte cell line (HaCat) and human fibroblast cell line (BJ) after incubation with IMC only, IMC phospholipid complex (IMC/PC), IMC phospholipid complex with various PVP contents (mean \pm SD, $n=4)$ 


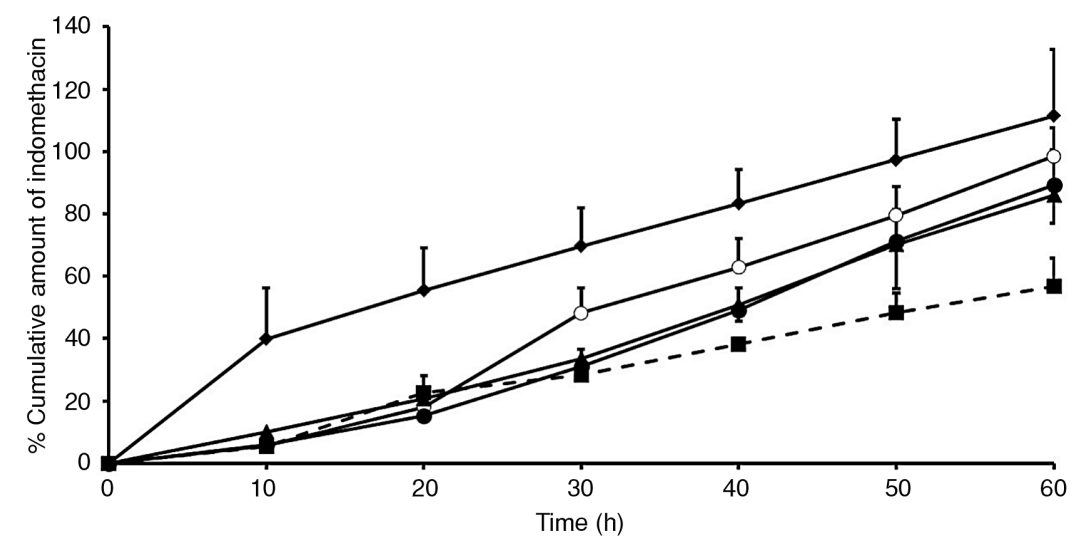

Figure 8. Permeation of indomethacin (IMC) across with human keratinocyte cells: IMC only (black square), IMC phospholipid complex (black diamond), IMC phospholipid complex with 0.5\% PVP (white circle), IMC phospholipid complex with $1.0 \%$ PVP (black circle) and IMC phospholipid complex with $2.0 \%$ PVP (black triangle) (mean $\pm \mathrm{SD}, \mathrm{n}=3$ )

IMC in phospholipid complex with PVP) show differences in their structures. The IMC spray produced 2-5 $\mu \mathrm{m}$ size of phospholipid complex (Fig. 4). According to the TEM, the IMC was possibly covered by a shell of phospholipids.

The FT-IR spectrum of Indomethacin formulations spray

The FT-IR spectrum of IMC, IMC in a liposome, IMC in a liposome and Kollidon VA64 (PVP) $(0.5 \%, 1.0 \%$ and $2.0 \% \mathrm{w} / \mathrm{w}$, respectively) and PVP are shown in Figure 5. The IR spectrum of IMC shows the $\mathrm{O}-\mathrm{H}$ stretching and sharp peak of $\mathrm{C}=\mathrm{O}$ stretching at 3456 and $1689 \mathrm{~cm}^{-1}$, respectively. For $\mathrm{IMC}$ in a liposome, the peak of $\mathrm{O}-\mathrm{H}$ stretching at $3445 \mathrm{~cm}^{-1}$ and the sharp peak of $\mathrm{C}-\mathrm{H}$ stretching at $2924 \mathrm{~cm}^{-1}$ were obtained. For Kollidon VA64 showed the presence of peak stretching band of $\mathrm{C}-\mathrm{H}$ stretching at $2958 \mathrm{~cm}^{-1}$ and $\mathrm{C}=\mathrm{O}$ at 1733 and 1662 $\mathrm{cm}^{-1}$, respectively. Pure IMC : Liposome : PVP mixtures, the peak of C-H stretching at $3421-3417 \mathrm{~cm}^{-1}$, $2924 \mathrm{~cm}^{-1}$ and the sharper peak of $\mathrm{C}=\mathrm{O}$ stretching at 1733 and $1658-1647 \mathrm{~cm}^{-1}$ were obtained. Increasing concentration of Kollidon VA64 raised the peak of $\mathrm{C}-\mathrm{H}$ stretching at $2924 \mathrm{~cm}^{-1}$ and $\mathrm{C}=\mathrm{O}$ stretching at $1658-1647 \mathrm{~cm}^{-1}$.

\section{In vitro IMC release profile}

The phospholipid complex with $0.5 \%$ PVP exhibited the highest drug release in comparison to the other concentrations of PVP (Fig. 6). However, the phospholipid complex without the PVP provided lower IMC release than the combined film-forming agent.

\section{Cytotoxicity assay}

After incubation of $\mathrm{HaCaT}$ with the IMC formulations, the percent viability of the cells was higher than the IMC. The pure IMC expressed cytotoxicity to the human keratinocytes. The pure IMC also expressed slight toxicity to human fibroblast cells (Fig. 7). Whereas, the phospholipid complex formulations provided a percent cell viability close to $100 \%$, which indicated the safety of the formulations for topical administration. The incorporation of PVP as a film-forming agent also showed no toxicity to the fibroblast cells.

\section{Transport assay}

There is evidence that IMC can permeate across keratinocytes. Figure 8 shows that the IMC phospholipid complex formulation gave higher permeation than IMC alone. While the effect of the film-forming agent retarded the drug permeation as a thicker barrier (with 1\% PVP and 2\% PVP) gave only $80 \%$ permeation at $24 \mathrm{~h}$.

\section{DISCUSSION AND CONCLUSION}

The IMC-pressurized spray was successfully developed by incorporation of phospholipid and a film-forming agent. The incorporation of a phospholipid and PVP miniaturized the spray droplets. The viscosities of the formulations increased as the PVP concentration increased. The phospholipid complex may fuse the droplets together by an interaction between the phospholipid complex and PVP present in the system. The larger contact angles could stabilize the droplet formation that was sup- 
ported by the spray pattern. Complete coverage of the film on the glass slide was observed by SEM in the PVP incorporated system. The IMC in ethanol had crystallized particles that indicated particle precipitation after spraying. A smoother film formation surface on the sampling slide was observed when incorporating a phospholipid complex system with PVP (22). It was not possible to measure the particle size of the solution in the HFA-134a system. The simulated system with a solvent of a similar dielectric constant close to HFA-134a is methylene chloride. Thus, the measured particle size was the size of spray formulation containing all ingredients except the propellant HFA-134a which was replaced by the methylene chloride. The addition of PVP reduced the hydrodynamic particle size possibly due to the properties of the PVP that help the IMC phospholipid complex to form more spherical particles with a smaller and more consistent size distribution (24).

Smooth film formation without IMC crystallization was obtained under SEM. The phospholipid complex and lipid-based system could protect the IMC from precipitation and crystallization by the encapsulating effect (25-27). Therefore, this system could provide higher solubility of the IMC. TEM results confirmed that the phospholipid complex was formed as the spherical formation of the phospholipid complex with the PVP after the formulation had been sprayed from the pressurized system and dried out (28-29).

The drug release from the sprayed film showed that the lower PVP concentration gave better drug release. Hence, a certain concentration of PVP may prevent IMC release. The lowest IMC releases were observed in the IMC phospholipid complex and IMC alone. This might be due to an interaction between IMC, liposome and Kollidon VA64. PVP had improved the dissolution of the IMC phospholipid complex related to the PVP concentration (30). Since the PVP provides better film formation, it also forms a barrier. At a certain concentration, it may also retard the dissolution (31). This may be explained by the IMC phospholipid complex that cannot improve IMC release.

The percent viabilities of the human keratinocytes and fibroblasts demonstrated the safety of the formulations over the pure IMC. The mechanism of NSAID toxicity to fibroblast cells includes inhibiting the production of hyaluronic acid, thereby reducing fibroblast activity (32-34). The inhibition of Pglycoprotein by the IMC formulation may not lead to cellular toxicity (35). There are many drug delivery systems which have used a phospholipid complex to reduce the drug toxicity during drug administration
$(23,36,37)$. These results also confirmed the safety of using PVP as the film-forming agent (38). According to the results of cell viability, all formulations provided almost $100 \%$ viability in the human keratinocyte and fibroblast cell lines. The permeation of IMC was increased by the phospholipid complexPVP incorporated formulation acted as a permeation enhancer and through direct vesicle fusion (39).

\section{Acknowledgments}

The authors would like to thank the Drug Delivery System Excellence Centre for providing facilities. This work was supported by the National Research University Research Project (Grant Number PHA580540S), Prince of Songkla University, Thailand. This research was also supported by the Postdoctoral Fellowship at Prince of Songkla University.

\section{REFERENCES}

1. Bascones-Martínez A., Muńoz-Corcuera M., Bascones-Ilundain C.: Med. Clínica Engl. Ed. 144, 126 (2015).

2. Lione A., Scialli A.R.: Reprod. Toxicol. 9, 7 (1995).

3. Yadav S.K., Adhikary B., Chand S., Maity B., Bandyopadhyay S.K. et al.: Free Radic. Biol. Med. 52, 1175 (2012).

4. Hadgraft J., Du Plessis J., Goosen C.: Int. J. Pharm. 207, 31 (2000).

5. Cordero J., Camacho M., Obach R., Domenech J., Vila L.: Eur. J. Pharm. Biopharm. 51, 135 (2001).

6. Fujii M., Shiozawa K., Henmi T., Yamanouchi S., Suzuki H. et al.: Int. J. Pharm. 137, 117 (1996).

7. Elnaggar Y.S.R., El-Refaie W.M., El-Massik M.A., Abdallah O.Y.: J. Control. Release. 180, 10 (2014).

8. Limón D., Amirthalingam E., Rodrigues M., Halbaut L., Andrade B. et al.: Eur. J. Pharm. Biopharm. 96, 421 (2015).

9. Elmowafy M., Samy A., Abdelaziz A.E., Shalaby K., Salama A. et al.: Beni-Suef Univ. J. Basic Appl. Sci. 6, 184 (2017).

10. Niamprem P., Srinivas S.P., Tiyaboonchai W.: Asian Fed. Pharm. Sci. AFPS 2015 Conf. 11, 174 (2016).

11. Chen Y.Y., Lu Y.H., Ma C.H., Tao W.W, Zhu J.J. et al.: Biomed. Pharmacother. 87, 82 (2017).

12. Akhtar N., Khan R.A.: Prog. Lipid Res. 64, 192 (2016). 
13. Shah M.R., Imran M., Ullah S.: Chapter 3 Liposomes, in: Lipid-Based Nanocarriers for Drug Delivery and Diagnosis, p. 63, William Andrew Publishing 2017.

14. Manconi M., Caddeo C., Sinico C., Valenti D., Mostallino M.C. et al.: Eur. J. Pharm. Biopharm. 78, 27 (2011).

15. Budai L., Kaszás N., Gróf P., Lenti K., Maghami K. et al.: Sci. Pharm. 81, 1151 (2013).

16. Betz G., Aeppli A., Menshutina N., Leuenberger H.: Int. J. Pharm. 296, 44 (2005).

17. Van Echteld C.J.A., De Kruijff B., Mandersloot J.G., De Gier J.: Biochim. Biophys. Acta Biomembr. 649, 211 (1981).

18. Liang X., Mao G., Ng K.Y.S.: J. Colloid Interface Sci. 278, 53 (2004).

19. Komatsu H., Okada S.: Chem. Phys. Lipids 85, 67 (1997).

20. Zurdo Schroeder I., Franke P., Schaefer U.F., Lehr C.M.: Eur. J. Pharm. Biopharm. 65, 111 (2007).

21. Mellert W., Deckardt K., Gembardt C., Hildebrand B., Schulte S.: Food Chem. Toxicol. 42, 1573 (2004).

22. Ma X.F., Xie G.Z., Su Y.J., Du H.F., Xie T. et al.: Sci. China Technol. Sc. 59, 1377 (2016).

23. Sintov A.C., Botner S.: Int. J. Pharm. 311, 55 (2006).

24. Khanniri E., Sohrabvandi S., Arab S.M., Shadnoush M., Mortazavian A.M.: Koomesh 19, 144 (2017).

25. Chen Y., Lu Y., Chen J., Lai J., Sun J. et al.: Int. J. Pharm. 376, 153 (2009).
26. Gangadhar K.N., Adhikari K., Srichana T.: Int. J. Pharm. 471, 430 (2014).

27. Mugabe C., Azghani A.O., Omri A.: Int. J. Pharm. 307, 244 (2006).

28. Nguyen H.T., Tran T.H., Thapa R.K., Phung C.D., Shin B.S. et al.: Int. J. Pharm. 527, 61 (2017).

29. Wytrwal M., Bednar J., Nowakowska M., Wydro P., Kepczynski M.: Colloids Surf. B Biointerfaces 120, 152 (2014).

30. Paradkar A., Ambike A.A., Jadhav B.K., Mahadik K.R.: Int. J. Pharm. 271, 281 (2004).

31. Doherty C., York P.: Int. J. Pharm. 34, 197 (1987).

32. August E.M., Nguyen T., Malinowski N.M., Cysyk R.L.: Cancer Lett. 82, 49 (1994).

33. Nguyen K.D., Lee D.A.: Invest. Ophthalmol. Vis. Sci. 33, 2693 (1992).

34. Elias J.A.: Am. Rev. Respir. Dis. 138, 652 (1988).

35. Yu L., Wu W.K.K., Li Z.J., Liu Q.C., Li H.T. et al.: Mol. Pharmacol. 75, 1364 (2009).

36. Malam Y., Loizidou M., Seifalian A.M.: Trends Pharmacol. Sci. 30, 592 (2009).

37. O'Brien M.E., Wigler N., Inbar M., Rosso R., Grischke E. et al.: Ann. Oncol. 15, 440 (2004).

38. Roh J., Han M., Kim K.N., Kim K.M.: Dent. Mater. J. 35, 601 (2016).

39. Fang J.Y., Hong C.T., Chiu W.T., Wang Y.Y.: Int. J. Pharm. 219, 61 (2001).

Received: 29.08. 2018 